\title{
Simultaneous Expression of PDH45 with EPSPS Gene Improves Salinity and Herbicide Tolerance in Transgenic Tobacco Plants
}

\author{
Bharti Garg', Sarvajeet S. Gill', Dipul K. Biswas ${ }^{1}$, Ranjan K. Sahoo', \\ Nandkumar S. Kunchge ${ }^{3}$, Renu Tuteja ${ }^{1}$ and Narendra Tuteja ${ }^{1,4 *}$ \\ ${ }^{1}$ International Centre for Genetic Engineering and Biotechnology, New Delhi, India, ${ }^{2}$ Stress Physiology and Molecular \\ Biology Lab, Centre for Biotechnology, Maharshi Dayanand University, Rohtak, India, ${ }^{3}$ Bejo Sheetal Seeds Pvt. Ltd, Jalna, \\ India, ${ }^{4}$ Amity Institute of Microbial Technology, Amity University Uttar Pradesh, Noida, India
}

\section{OPEN ACCESS}

Edited by:

Sagadevan G. Mundree, Queensland University of Technology,

Australia

Reviewed by:

Taras P. Pasternak,

Albert Ludwig University of Freiburg,

Germany

Vasileios Fotopoulos,

Cyprus University of Technology, Cyprus

${ }^{*}$ Correspondence: Narendra Tuteja ntuteja@icgeb.res.in; ntuteja@amity.edu

Specialty section: This article was submitted to

Plant Biotechnology, a section of the journal

Frontiers in Plant Science

Received: 14 August 2016 Accepted: 01 March 2017

Published: 24 March 2017

Citation:

Garg B, Gill SS, Biswas DK, Sahoo RK, Kunchge NS, Tuteja $R$ and Tuteja N (2017) Simultaneous Expression of PDH45 with EPSPS Gene Improves Salinity and Herbicide

Tolerance in Transgenic Tobacco Plants. Front. Plant Sci. 8:364. doi: 10.3389/fpls.2017.00364
To cope with the problem of salinity- and weed-induced crop losses, a multi-stress tolerant trait is need of the hour but a combinatorial view of such traits is not yet explored. The overexpression of PDH45 (pea DNA helicase 45) and EPSPS (5enoylpruvyl shikimate-3-phosphate synthase) genes have been reported to impart salinity and herbicide tolerance. Further, the understanding of mechanism and pathways utilized by PDH45 and EPSPS for salinity and herbicide tolerance will help to improve the crops of economical importance. In the present study, we have performed a comparative analysis of salinity and herbicide tolerance to check the biochemical parameters and antioxidant status of tobacco transgenic plants. Collectively, the results showed that $P D H 45$ overexpressing transgenic lines display efficient tolerance to salinity stress, while PDH45+EPSPS transgenics showed tolerance to both the salinity and herbicide as compared to the control [wild type (WT) and vector control (VC)] plants. The activities of the components of enzymatic antioxidant machinery were observed to be higher in the transgenic plants indicating the presence of an efficient antioxidant defense system which helps to cope with the stress-induced oxidative-damages. Photosynthetic parameters also showed significant increase in $P D H 45$ and $P D H 45+E P S P S$ overexpressing transgenic plants in comparison to WT, VC and EPSPS transgenic plants under salinity stress. Furthermore, $\mathrm{PDH} 45$ and $P D H 45+E P S P S$ synergistically modulate the jasmonic acid and salicylic acid mediated signaling pathways for combating salinity stress. The findings of our study suggest that pyramiding of the PDH45 gene with EPSPS gene renders host plants tolerant to salinity and herbicide by enhancing the antioxidant machinery thus photosynthesis.

Keywords: EPSPS, PDH45, salinity, herbicide tolerance, tobacco

\section{INTRODUCTION}

Being sessile, plants are confronted with a wide range of environmental cues on regular basis, which eventually impose serious constraints on growth and development, thus productivity. Among major abiotic stress factors, salinity and weed stress are the major environmental challenges restricting plant growth and agricultural productivity in large (Mahajan and Tuteja, 2005; Funke et al., 2006; Tuteja, 2007). At molecular level, these abiotic stresses emerge as quantitative traits, 
which are generally regulated by multiple genes rather than a single gene. However, literature also revealed that only single gene manipulation can also impart significant stress tolerance in plants (Cushman and Bohnert, 2000; Zhang and Blumwald, 2001; Sanan-Mishra et al., 2005; Vashisht et al., 2005; Huda et al., 2013; Tuteja et al., 2013).

The development of transgenic plants through genetic manipulations has proved promising to reduce agricultural losses due to various abiotic stress factors, which eventually resulted in improved crop productivity (Mittler et al., 2004; Gill et al., 2014). The role of DNA/RNA helicases have also emerged in salinity stress tolerance (Vashisht and Tuteja, 2006; Gill et al., 2013; Owttrim, 2013; Tuteja et al., 2013). Helicases unwind the duplex nucleic acids and are involved in multitude of vital processes including replication, repair, recombination, and transcription (Tuteja and Tuteja, 2004; Tuteja et al., 2012). In this pursuit, our laboratory has explored the over expression and characterization of some of the helicase genes such as PDH45, PDH47, SUV3, and $p 68$ toward the development of salinity tolerant tobacco and rice transgenic plants without yield penalty (Sanan-Mishra et al., 2005; Vashisht et al., 2005; Amin et al., 2012; Gill et al., 2013; Tuteja et al., 2013, 2014; Banu et al., 2015).

Besides salinity stress, weeds are also considered as one of the potent contributors in reducing the agricultural productivity by competing with the Crop plants of interest for nutrition, thus affect its growth and productivity (Délye et al., 2013). Most of the herbicides control weeds by inhibiting specific enzymes by binding at the active site of the enzyme, also target photosynthesis and lipid biosynthesis (Cole et al., 2000; Wakabayashi and Böger, 2002). Literature reveals that there are two types of herbicide resistance mechanisms in plants. Target site resistance (TSR), where mutation/alteration in a gene encodes a structural change in its gene product so that herbicide cannot function in inhibitory manner, whereas, the phenomenon of non-targetsite resistance (NTSR) is little understood and can impart unpredictable resistance by any mechanism not belonging to TSR (Délye, 2013; Sammons and Gaines, 2014). The use of glyphosate in agriculture has increased enormously since the introduction of glyphosate-resistant crop plants because it helps in weed control and thus improves the yield and profitability (Funke et al., 2006; Duke and Powles, 2008; Green, 2012). Further, glyphosate is a broad spectrum herbicide which inhibits the biosynthesis of the aromatic amino acids (tryptophan, tyrosine, and phenylalanine) by inhibiting the activity of EPSPS (5-enoylpruvyl shikimate-3phosphate synthase), a key enzyme of shikimate pathway (Gomes et al., 2014). Literature reports that EPSPS overexpression provides high glyphosate tolerance in Escherichia coli and tobacco plants (Cao et al., 2013). Recently, Chhapekar et al. (2015) reported that overexpression of codon-optimized CP4-EPSPS helped rice to tolerate up to $1 \%$ commercial glyphosate. Further, stacking of Bt crylAh and mG2-epsps gene linked with LP4/2A showed higher expression and possessed good pest resistance and glyphosate tolerance in tobacco than those linked by 2A (Sun et al., 2012). The EPSPS gene has been isolated and characterized from mutant Rye grass (Lolium rigidum) (Simarmata and Penner, 2008) where mutation at nucleotide 301 (Cytosine to Thymine) of truncated EPSPS gene leads to change in amino acid code from Proline to Serine leading to the development of glyphosate tolerance. These observations confirm that EPSPS could be a good candidate for the development of herbicide tolerant crops. It will be beneficial to develop multi-stress tolerant transgenic plants which harbor tolerance to both salinity and herbicide.

Therefore, we designed a single construct containing both PDH45 (salinity tolerance) + EPSPS (herbicide tolerance) genes and introduced it into tobacco plants. The transgenic plants overexpressed both the genes and provide salinity and herbicide tolerance. Furthermore, the literature suggests that transgenic plants overexpressing $\mathrm{PDH} 45$ gene provide only salinity tolerance while EPSPS gene transgenics provide only herbicide tolerance.

\section{MATERIALS AND METHODS}

\section{Plasmids Construction and Transformation of Tobacco Plants}

The complete ORF of PDH45 cDNA (1.2 kb; Accession number Y17186.1) was PCR amplified using the gene specific primers (Supplementary Table S1) and cloned into pGEM-T easy vector (Promega). The PDH45 gene fragment was isolated from pGEM-T-PDH45 plasmid and ligated into the MCS of pRT101 vector. The CaMV35S-PDH45-poly-A fragment from pRT101-PDH45 plasmid was isolated and ligated into the MCS of the binary vector pCAMBIA1302 which resulted in formation of construct pCAMBIA1302-PDH45 (Figure 1A). The Rye grass mutant EPSPS isolate from Lolium rigidum was PCR amplified (Supplementary Table S1) and cloned into pGEM-T easy vector. Further the EPSPS fragment was cloned into pCAMBIA1302 vector in place of GFP reporter, which resulted in the construction of a plasmid, pCAMBIA1302-EPSPS (Figure 1B). For the formation of dual gene (PDH45+EPSPS) construct, the $1.2 \mathrm{~kb}$ EPSPS gene fragment was cloned into pCAMBIA1302-PDH45 plasmid in place of GFP, which resulted in construction of a dual gene plasmid, pCAMBIA1302-PDH45-EPSPS (Figure 1C). Transformation of tobacco plants (Nicotiana tabacum) with Agrobacterium tumefaciens (LBA4404) containing the single or dual genes constructs (pCAMBIA1302-PDH45, pCAMBIA1302EPSPS, or pCAMBIA1302-PDH45-EPSPS) was performed by using high frequency regeneration via direct somatic embryogenesis and efficient Agrobacterium-mediated genetic transformation method as described recently (Pathi et al., 2013). Competent strain of Agrobacterium tumefaciens (LBA4404) was transformed with the empty vector (pCAMBIA1302) construct as vector control (VC, the vector pCAMBIA-1302) using standard protocols. The empty vector contained all except the gene of interest. Non-transformed tobacco plant (Nicotiana tabacum) was also taken as control wild type (WT) plants.

\section{PCR and Southern Hybridization}

Genomic DNA was isolated by CTAB method ( $N$-acetyl$N, N, N$-trimethyl ammonium bromide). PCR amplification was performed to amplify the $1.2 \mathrm{~kb}$ fragment of PDH45 and EPSPS by using gene specific primers (Supplementary Table S1). 

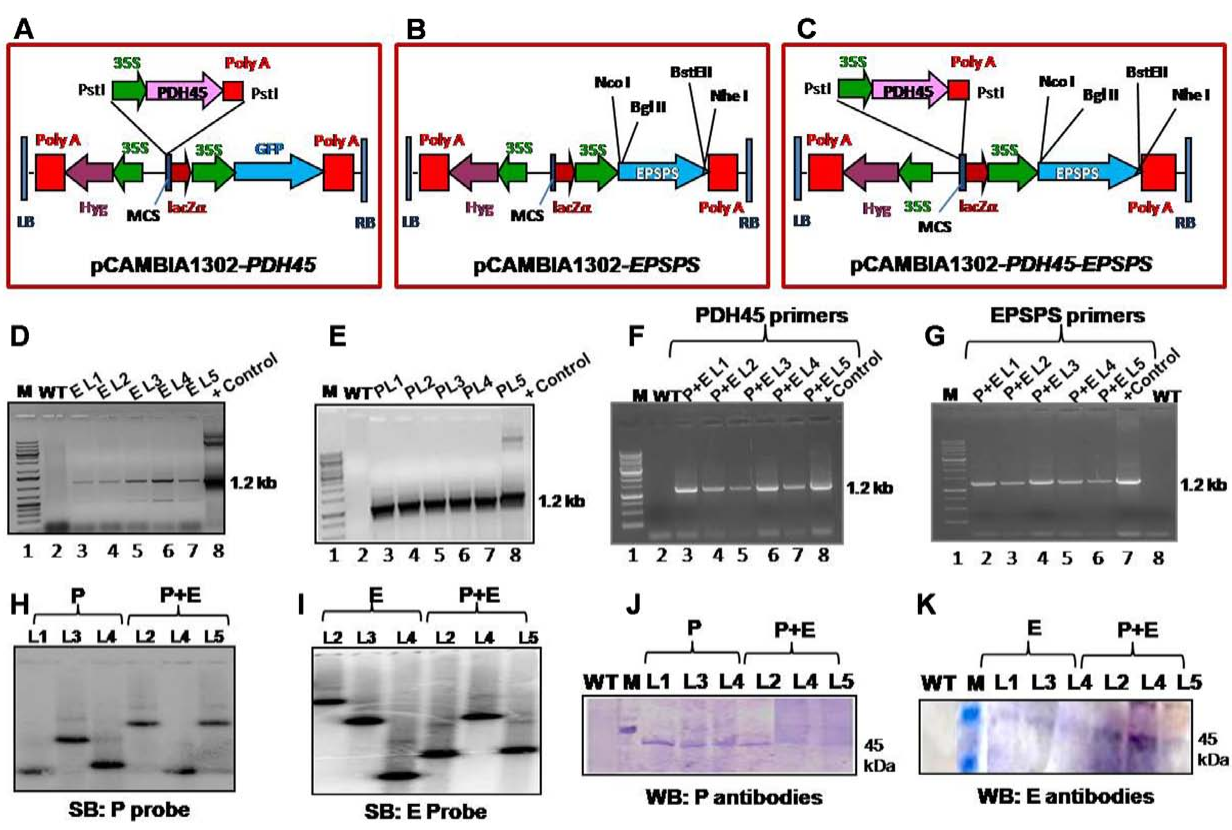

$\mathbf{J}$

L

SB: EP

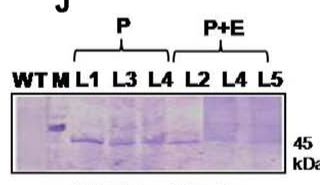

K
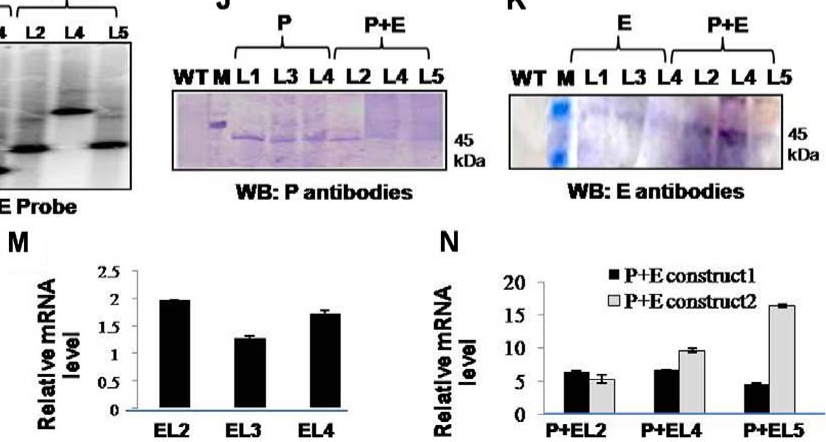

FIGURE 1 | Analysis of $\mathrm{T}_{1}$ transgenic lines (L1-L5) to confirm stable integration of transgene and the expression of gene. (A-C) Schematic representation of map of pCAMBIA1302-PDH45, pCAMBIA1302-EPSPS and pCAMBIA1302-PDH45+EPSPS constructs used to overexpress PDH45 and EPSPS CDNA in tobacco plants. (D) PCR confirmation of EPSPS T 1 transgenic plants by using EPSPS (E) gene specific primers. (E) PCR confirmation of PDH45 (P) transgenic plants by using PDH45 gene specific primers. (F) PCR confirmation of PDH45+EPSPS (P+E) double transgenic plants by using PDH45 gene specific primers. (G) PCR confirmation of PDH45+EPSPS double transgenic plants by using EPSPS gene specific primers. (H,I) Southern blot analysis to show the copy number of PDH45 and EPSPS gene in tobacco transgenic plants. (J) Western blot analysis using anti-PDH45 antibodies. (K) Western blot analysis using anti-EPSPS antibodies. (L) QPCR analysis of $P D H 45$ transgenics with gene specific primers. (M) QPCR analysis of EPSPS transgenics with gene specific primers. (N) Expression analysis of PDH45+EPSPS overexpressing lines with $P D H 45$ and EPSPS genes specific primers. P+E construct 1 represents the expression analysis in $P D H 45+E P S P S$ transgenics with $P D H 45$ gene specific primers. $\mathrm{P}+\mathrm{E}$ construct 2 represents the expression analysis in PDH45+EPSPS transgenics with EPSPS gene specific primers. $P, E$ and $P+E$ represent the same.

Furthermore, $50 \mu \mathrm{g}$ of genomic DNA from PCR positive transgenic lines was digested with $\mathrm{XbaI}$ for $\mathrm{PDH} 45$ and EPSPS, electrophoresed and blotted on nylon transmembrane (Amersham) as described (Sanan-Mishra et al., 2005). Complete radiolabeled ORF of $P D H 45$ and EPSPS cDNA was used as a probe.

\section{Western Blotting and qPCR Analysis}

Total soluble proteins from the leaf tissues of WT and transgenic lines were resolved on to the 10\% SDS-PAGE and further transferred to PVDF (Amersham) membrane followed by Western blot by using PDH45 (Pham et al., 2000; Sanan-Mishra et al., 2005) and EPSPS (GenScript USA, Inc.) specific (1:10,000 dilution) antibodies.

The expression analysis of PDH45 and EPSPS mRNA was analyzed by qPCR. Total RNA was isolated from 14 days old seedlings of WT and transgenic (PDH45, EPSPS, or PDH45+EPSPS) plants exposed to $200 \mathrm{mM} \mathrm{NaCl}$ by using TriZol reagent (Sanan-Mishra et al., 2005). Actin was used as an internal control and primers used for qPCR are listed in Supplementary Table S1. qPCR was done as described earlier (Garg et al., 2012).

\section{Leaf Disk Senescence Assay and Chlorophyll Estimation}

Healthy and fully expanded leaves of WT, VC and transgenic tobacco plants (45 days old) were used to take the $10 \mathrm{~mm}$ circular disks. The disks were allowed to float in $6 \mathrm{ml} \mathrm{NaCl}$ and $\mathrm{H}_{2} \mathrm{O}$ (control) for $72 \mathrm{~h}$ and analyzed as described (Tuteja et al., 2013). Furthermore, the same disks were further used for chlorophyll estimation (Tuteja et al., 2013) and represented as \% chlorophyll retained.

\section{Seedling Establishment and Growth Parameters}

To check seedling establishment potential, root growth and fresh weight, the seeds of WT, VC and transgenic tobacco plants were chosen to determine the effects of salinity stress. Sterilized 
tobacco seeds of transgenic along with WT and VC were sown in Petri dishes (100 seeds per sample) containing full strength Murashige-Skoog (MS) solid medium ( $\mathrm{pH}$ 5.8) supplemented with $200 \mathrm{mM} \mathrm{NaCl}$ and $30 \mathrm{mg} / \mathrm{L}$ hygromycin for salinity stress and selection marker, respectively. The number of germinated seeds was counted on daily basis, as it was defined as the emergence of the hypocotyls from 1 to 16 days. Measurement of root length $(\mathrm{cm})$ and fresh weight $(\mathrm{mg} /$ plant) were taken at every sampling and all the measurements were carried out in triplicates. Seedlings stressed with $200 \mathrm{mM} \mathrm{NaCl}$ were later transferred to vermiculite pots and allowed to grow in green house $(16 \mathrm{~h}$ light $/ 8 \mathrm{~h}$ dark) at $25^{\circ} \mathrm{C}$ and were irrigated at every 10 th day with $200 \mathrm{mM} \mathrm{NaCl}$ solution for 3 months.

\section{Glyphosate Tolerance by EPSPS Overexpressing Tobacco Plants}

Seeds of various transgenics (PDH45, EPSPS, or PDH45+EPSPS), $\mathrm{VC}$ and WT were germinated on $1 \mathrm{mM}$ glyphosate and fresh weights were recorded. The four to five leaf stage tobacco transgenic plants were sprayed with $1 \%(\mathrm{v} / \mathrm{v})$ solution herbicide Roundup containing $41 \%$ glyphosate (Isopropyl amine salinity, Monsanto, Inc.) for different time points of post-treatment and accumulation of shikimic acid was estimated according to Cao et al. (2013).

\section{Measurement of ROS and Antioxidant Enzymes}

Various oxidative stress markers [malondialdehyde (MDA); hydrogen peroxide $\left(\mathrm{H}_{2} \mathrm{O}_{2}\right)$ and electrolytic leakage], and antioxidant enzymes [like catalase (CAT); ascorbate peroxidase (APX); glutathione reductase (GR)], proline and RWC (relative water content) were estimated in transgenic lines, VC and WT plants by using the methods described earlier (Garg et al., 2012). The nitroblue tetrazolium (NBT) (N6876, Sigma-Aldrich) and 3, 3 diaminobenzidine (DAB) (D5637, Sigma-Aldrich) stains were used to check the accumulation of superoxide radicals $\left(\mathrm{O}_{2}{ }^{--}\right)$and $\mathrm{H}_{2} \mathrm{O}_{2}$, respectively (Dong et al., 2009). For $\mathrm{O}_{2}{ }^{--}$accumulation, seedlings were vacuum infiltrated with $0.1 \mathrm{mg} \mathrm{ml}^{-1}$ NBT in $25 \mathrm{mM}$ Hepes buffer ( $\mathrm{pH}$ 7.6) and incubated for $2 \mathrm{~h}$ at room temperature in the dark. The samples were then transferred to $80 \%$ ethanol and treated at $70^{\circ} \mathrm{C}$ for $10 \mathrm{~min}$. For $\mathrm{H}_{2} \mathrm{O}_{2}$ accumulation, seedlings were vacuum infiltrated with $0.1 \mathrm{mg} \mathrm{ml}^{-1} \mathrm{DAB}$ in $50 \mathrm{mM}$ Tris-acetate buffer ( $\mathrm{pH} \mathrm{5.0)}$ ) and incubated for $24 \mathrm{~h}$ at room temperature in the dark before transferring to $80 \%$ ethanol (Dong et al., 2009).

\section{Measurement of Photosynthetic Characteristics}

Various photosynthetic parameters were recorded in fully expanded mature leaves using infra-red gas analyzer (IRGA, LiCor, Lincoln, NE, USA) during the sunny day between 10:00 and 11:00 $\mathrm{h}$ at atmospheric conditions.

\section{qPCR of SA and JA Pathway}

To understand mechanism of stress tolerance in PDH45 or PDH45+EPSPS overexpressing transgenic lines, the RNA from
3 to 5 days old WT, VC and transgenic tobacco seedlings was isolated. Sequence of 19 sets of genes related to different abiotic stress makers and hormonal pathways were downloaded from NCBI to design the primers (Supplementary Table S1) and qPCR was performed (Garg et al., 2012). For further confirmation of transgenics, VC and WT, seeds were grown in MS medium, $10 \mu \mathrm{M}$ MeJ, $2 \mu \mathrm{M}$ salicylic acid (SA), or combination of $10 \mu \mathrm{M}$ $\mathrm{MeJ}+2 \mu \mathrm{M}$ SA.

\section{Statistical Analysis}

All the experimental data obtained are the means of three independent experiments under the same environmental condition and the results are shown as mean with standard error (mean $\pm \mathrm{SE}$ ). One way analysis of variance was used to test the significance between the mean values of control and transgenic plants and comparison among means was carried out using Tukey-Kramer multiple comparisons test with the help of Graph-Pad Instat software (ver 3.0). Statistically significant threshold was fixed to $P<0.05, P<0.01$, or $P<0.001$.

\section{RESULTS}

\section{PDH45, EPSPS, or PDH45+EPSPS Overexpression in Tobacco Plants}

To elucidate the functional significance of PDH45 and EPSPS in one system, the complete ORF of pea PDH45 (SananMishra et al., 2005) and Rye grass EPSPS were overexpressed in tobacco plants. As a VC, the only vector (pCAMBIA-1302) was transformed in tobacco and the transgenic plants were generated at the same time under the same conditions as the plants containing the vector along with PDH45 and/or EPSPS the gene(s). The map of T-DNA single gene constructs (PDH45 and EPSPS) and double gene construct (PDH45+EPSPS) used for raising transgenic tobacco plants were shown in (Figures 1A-C). The $\mathrm{T}_{1}$ and $\mathrm{T}_{2}$ generation plants segregated in the expected ratios [3:1 and 9:3:3:1, respectively (Table 1)]. Analysis of transgenic lines was performed in the $T_{1}$ and $T_{2}$ generations. A total of five hygromycin resistant transgenic plants with single gene overexpressing lines (PDH45 or EPSPS) and double gene transgenics (PDH45+EPSPS) were confirmed by PCR using gene specific primers (Supplementary Table S1) and the expected size bands were obtained (Figures 1D-G). Three independent PCR positive lines of each set of transgenic plants were randomly selected for further analysis. Furthermore, the copy number of the integrated transgene in the single gene and double genes transgenic lines $\left(\mathrm{T}_{1}\right)$ were subjected to Southern blot analysis. The single copy integration was observed in all the three lines tested for PDH45 or EPSPS (Figures 1H,I). These results confirmed the integration of transgene (Figures $\mathbf{1 H}, \mathbf{I}$ ) in $T_{1}$ tobacco plants. The results of western blot analysis clearly showed the presence of $45 \mathrm{kDa}$ foreign protein in all the tested PDH45 and EPSPS transgenic lines (Figures 1J,K), but no band was observed in WT plants with the same antibodies (Figures 1J,K). The specific transcript expression was observed in the entire single ( $P D H 45$, Figure 1L) (EPSPS, Figure 1M) and double transgenic plants $(P D H 45+E P S P S$, Figure $\mathbf{1 N})$; actin was used 
TABLE 1 | Comparison of segregation ratio, seed number and weight of WT, VC, $\mathrm{T}_{1}$ and $\mathrm{T}_{2}$ transgenics of PDH45, EPSPS, and PDH45+EPSPS plants grown in the presence of $\mathrm{H}_{2} \mathrm{O}$ or $200 \mathrm{mM} \mathrm{NaCl}$, respectively.

\begin{tabular}{|c|c|c|c|c|c|c|}
\hline \multirow[t]{2}{*}{ Parameter } & \multirow[t]{2}{*}{ Generation } & \multicolumn{2}{|c|}{$\mathrm{H}_{2} \mathrm{O}$ grown control plants } & \multicolumn{3}{|c|}{ Transgenics grown in $200 \mathrm{mM}$ salt } \\
\hline & & Wild type & Vector control & PDH45 & EPSPS & $P D H 45+E P S P S$ \\
\hline Segregation ratio, $\mathrm{m}^{r}: \mathrm{m}^{\mathrm{s}}[\mathrm{n}]$ & $\mathrm{T}_{1}$ & 0 & $3.2: 1(155)$ & $3.18: 1(180)$ & $3.22: 1(160)$ & $3.11: 1(149)$ \\
\hline Segregation ratio, $\mathrm{m}^{\mathrm{r}}: \mathrm{m}^{\mathrm{s}}[\mathrm{n}]$ & $\mathrm{T}_{2}$ & 0 & $9.1: 3.2: 3.1: 1(270)$ & 9.1:2.18:3.1:1 (267) & 9.31:2.33:3.38:1 (254) & $9.22: 3.76: 3.12: 1$ \\
\hline Seed number per pod & $\mathrm{T}_{1}$ & $1567 \pm 1.19^{a}$ & $1565 \pm 1.15^{a}$ & $1568 \pm 0.92^{a}$ & $1568 \pm 1.76^{a}$ & $1566 \pm 0.88^{a}$ \\
\hline Seed number per pod & $\mathrm{T}_{2}$ & $1160 \pm 1.21^{\mathrm{a}}$ & $1160 \pm 1.54^{\mathrm{a}}$ & $1163 \pm 0.75^{a}$ & $1161 \pm 0.99^{a}$ & $1164 \pm 1.87^{a}$ \\
\hline Seed weight per pod (mg) & $\mathrm{T}_{1}$ & $117 \pm 2.05^{\mathrm{a}}$ & $118 \pm 0.778^{a}$ & $117 \pm 0.345^{a}$ & $115 \pm 1.42^{a}$ & $118 \pm 1.54^{\mathrm{a}}$ \\
\hline Seed weight per pod & $\mathrm{T}_{2}$ & $124 \pm 0.98^{a}$ & $123 \pm 2.05^{a}$ & $124 \pm 0.78^{a}$ & $125 \pm 1.65^{a}$ & $127 \pm 0.89^{a}$ \\
\hline
\end{tabular}

Each value represents mean of three replicates \pm SE. Results are expressed as means with standard deviation (mean \pm SD). The letters 'a' indicate non-significant

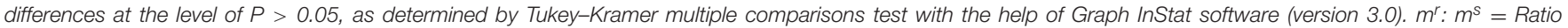
between resistant and susceptible plants grown in hygromycin plate. [n] = Total number of plants mentioned for each line in brackets.

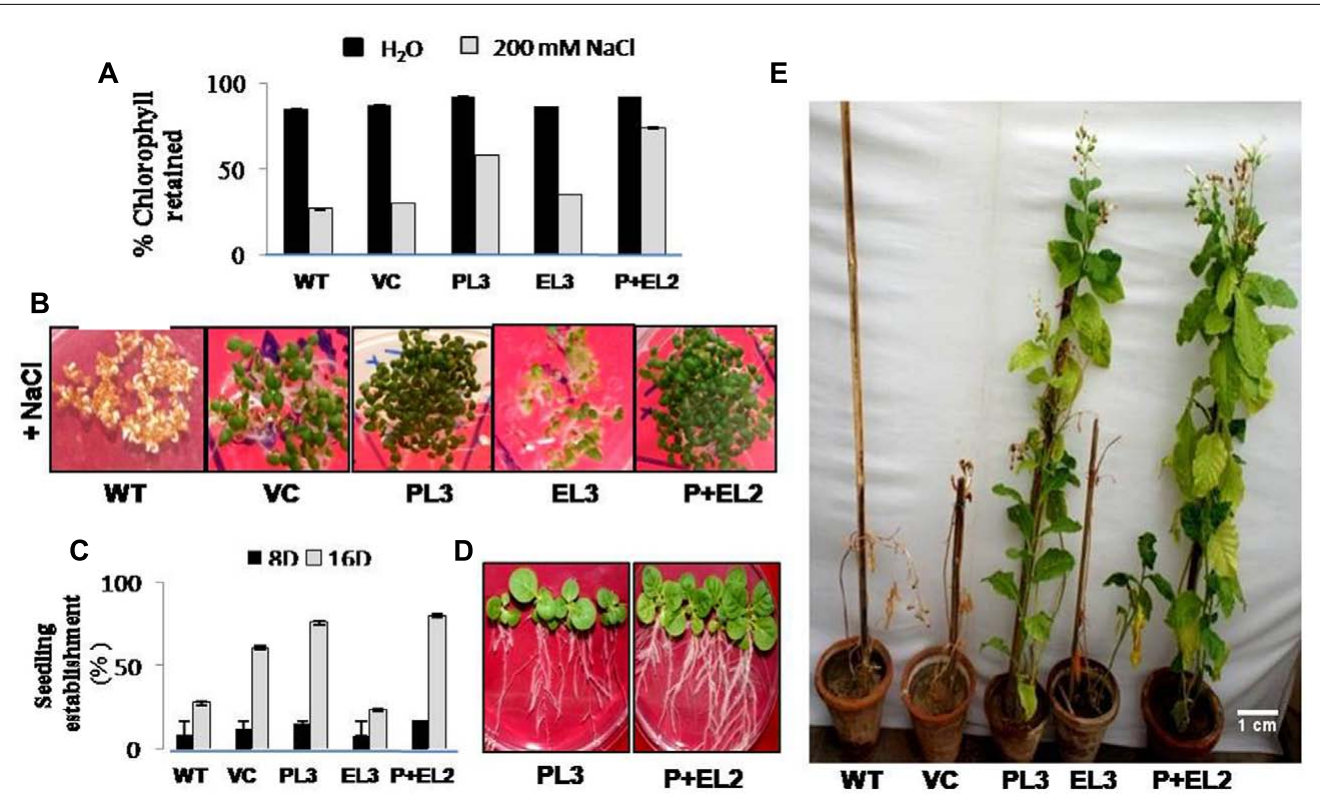

FIGURE 2 | Analysis of PDH45 (P), EPSPS (E) and PDH45+EPSPS (P+E) dual gene construct tobacco transgenics in salinity stress ( $\mathrm{T}_{1}$ generation). (A) Quantification of retained chlorophyll in the leaf disk of transgenic lines, VC and WT used for leaf senescence assay under $200 \mathrm{mM}$ salinity stress. (B) Seedling establishment of different transgenics (PDH45, EPSPS and PDH45+EPSPS) along with WT and VC in MS medium supplemented with $200 \mathrm{mM} \mathrm{NaCl}$.

(C) Representing \% germination rate in transgenic lines at different time points 8 and 16 days of post-treatment of $200 \mathrm{mM} \mathrm{NaCl}$. (D) Representative picture of transgenic tobacco (PL3 and P+EL2) seedling establishment. (E) Twenty days old tobacco transgenic seedlings (PDH45, EPSPS, and PDH45+EPSPS) were further transferred in vermiculite and irrigated with $200 \mathrm{mM} \mathrm{NaCl}$ at every 10 day for almost 3 months to further observe the effect of salinity stress on transgenics as compared to WT plants.

as internal control to normalize the expression intensity of all genes.

\section{Performance of $T_{1}$ Transgenic Plants under Salinity Stress}

To validate the salinity tolerance of single gene and double gene transgenics, leaf disk from the $\mathrm{T}_{1}$ transgenics and WT plants were floated separately in $200 \mathrm{mM} \mathrm{NaCl}$ and $\mathrm{H}_{2} \mathrm{O}$ (as control) for $72 \mathrm{~h}$. Salinity stress accompanied lesser loss of chlorophyll content in PDH45 or PDH45+EPSPS transgenic plants as compared to WT, VC and EPSPS alone plants (Figure 2A). These results explored the better ability of PDH45 or PDH45+EPSPS transgenic plants in confronting salinity stress.
Phenotypic comparison with $200 \mathrm{mM} \mathrm{NaCl}$ stress showed that WT, VC and EPSPS overexpressing seed did not germinate efficiently, whereas, PDH45 or PDH45+EPSPS overexpressing seeds germinated efficiently (Figure 2B). Figures 2A,B represent the results of one line of each transgenic plant; the other two lines also showed the same result. The PDH45 or PDH45+EPSPS transgenic lines also showed higher germination potential at 8th and 16th days as compared to WT, EV and EPSPS alone plants under $\mathrm{NaCl}$ stress (Figure 2C). Interestingly, under $200 \mathrm{mM} \mathrm{NaCl}$ stress, the growth of the PDH45+EPSPS transgenic seedlings was found to be better as compared to PDH45 alone transgenic seedlings (Figure 2D). Beyond that, salinity stress also resulted in reduced fresh weight and root length of WT, 
TABLE 2 | Comparison of various yield parameters obtained in transgenic $\left(\mathrm{T}_{1}\right.$ and $\mathrm{T}_{2}$ generation), wild type and vector control plants grown under $\mathrm{H}_{2} \mathrm{O}$ and $200 \mathrm{mM} \mathrm{NaCl}$, respectively.

\begin{tabular}{|c|c|c|c|c|c|c|}
\hline \multirow[t]{2}{*}{ Parameter } & \multirow[t]{2}{*}{ Generation } & \multicolumn{2}{|c|}{$\mathrm{H}_{2} \mathrm{O}$ grown control plants } & \multicolumn{3}{|c|}{ Transgenics grown in $200 \mathrm{mM} \mathrm{NaCl}$} \\
\hline & & Wild type & Vector control & PDH45 & EPSPS & PDH45+EPSPS \\
\hline Fresh weight of leaves & $\mathrm{T}_{1}$ & $0.57 \pm 1.23^{b}$ & $0.40 \pm 0.67^{c}$ & $4.50 \pm 2.13^{\mathrm{a}}$ & $0.45 \pm 0.95^{\mathrm{C}}$ & $4.8 \pm 0.36^{a}$ \\
\hline Fresh weight of leaves & $\mathrm{T}_{2}$ & $0.50 \pm 1.56^{d}$ & $0.50 \pm 1.65^{d}$ & $2.34 \pm 0.087^{a}$ & $0.60 \pm 0.87^{c}$ & $1.9 \pm 0.55^{b}$ \\
\hline Root length (cm) & $\mathrm{T}_{2}$ & $0.25 \pm 0.61^{d}$ & $0.30 \pm 1.41^{c}$ & $0.80 \pm 1.08^{b}$ & $0.30 \pm 0.56^{c}$ & $1.2 \pm 1.01^{a}$ \\
\hline Plant height (cm) & $\mathrm{T}_{1}$ & $35.6 \pm 1.9^{c}$ & $42.0 \pm 0.99^{b c}$ & $85 \pm 1.02^{\mathrm{a}}$ & $46.6 \pm 0.32^{b}$ & $87 \pm 2.13^{a}$ \\
\hline Plant height $(\mathrm{cm})$ & $\mathrm{T}_{2}$ & $48.0 \pm 2.34^{\mathrm{C}}$ & $43.0 \pm 1.54^{d}$ & $87 \pm 0.78^{a}$ & $54 \pm 1.54^{b}$ & $87.4 \pm 3.01^{a}$ \\
\hline Flowering time (D) & $\mathrm{T}_{1}$ & $119 \pm 1.12^{b}$ & $130 \pm 1.04^{a}$ & $112 \pm 1.06^{\mathrm{c}}$ & $117 \pm 1.15^{\mathrm{c}}$ & $109 \pm 2.11^{c}$ \\
\hline Flowering time (D) & $\mathrm{T}_{2}$ & $125 \pm 1.23^{a}$ & $128 \pm 1.65^{a}$ & $120 \pm 1.68^{a}$ & $128 \pm 1.15^{a}$ & $115 \pm 1.09^{b}$ \\
\hline
\end{tabular}

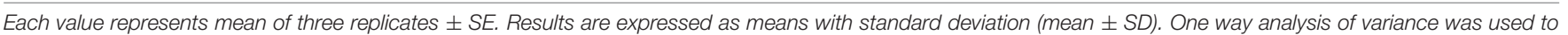

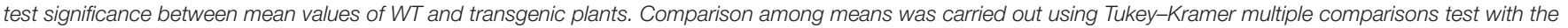

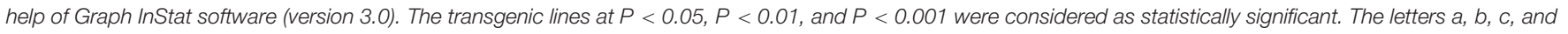
$d$ indicate significant differences.

VC and EPSPS transgenic plants as compared to PDH45 or PDH45+EPSPS transgenics (Table 2). Further to study the effect of PDH45 or PDH45+EPSPS overexpression in transgenic tobacco plants under salinity stress, the seedlings were transferred to soil and irrigated with $200 \mathrm{mM} \mathrm{NaCl}$ (every 10th day) for 3 months and several growth parameters such as plant height, fresh weight of leaves and time required for flowering were observed to be higher in PDH45 or PDH45+EPSPS (Table 2) tobacco transgenic plants in comparison to WT, VC and EPSPS only transgenic plants. Interestingly, it was observed that WT, VC or EPSPS transgenic plants failed to sustain growth in the presence of $\mathrm{NaCl}$ and eventually died, while the PDH45 or PDH45+EPSPS transgenic plants maintained regular growth rate, reached to maturity on time, flowered and set viable seeds (Figure $2 \mathbf{E}$ and Table 1 ). Overall, the PDH45 or PDH45+EPSPS lines grew normally under continuous stress and produced a yield comparable to WT plants grown in $\mathrm{H}_{2} \mathrm{O}$. However, WT plants did not survive until maturity under continuous stresses. These findings indicate that $\mathrm{PDH} 45$ or PDH45+EPSPS overexpression promotes salinity tolerance in tobacco.

\section{EPSPS or EPSPS+PDH45 Overexpressing Transgenic Tobacco Plants Showed Glyphosate Tolerance}

All the transgenics, WT or VC tobacco seedlings were grown vertically on the MS agar medium with or without $1 \mathrm{mM}$ glyphosate for 10-12 days. All the transgenic plants, WT or VC showed good growth on MS agar medium, however, the double genes transgenic (PDH45+EPSPS) performed superior (Figure 3A). But treatment with $1 \mathrm{mM}$ glyphosate inhibited the growth of WT, VC or transgenic plants overexpressing PDH45 (Figure 3A). Plants overexpressing EPSPS or PDH45+EPSPS genes grew more quickly and remained green till 10th day after treatment with $1 \mathrm{mM}$ glyphosate. The fresh weight of five independent transgenic plants for each gene was measured to assess the inhibition of plant growth by glyphosate (Figure 3B). The transgenic plants overexpressing EPSPS or PDH45+EPSPS genes had the highest fresh weight as compared to WT, VC and PDH45 transgenics (Figure 3B). To further confirm the glyphosate tolerance amongst the different transgenic plants, 6-8 leaf stage tobacco transgenic along with WT or VC plants were sprayed with $1 \%$ (v/v) solution herbicide Roundup containing $41 \%$ glyphosate at equal dose. The injury caused by glyphosate was recorded after 7, 14, or 21 days of post spray (DPS). All WT, VC or PDH45 (Figure 3C) transgenic plants showed severe injury and eventually died, whereas, transgenic plants containing EPSPS or PDH45+EPSPS genes remained healthy (Figure 3C). Furthermore, the leaves of same plants were used for shikimate estimation at 7, 14, or 21 DPS. In the present study, EPSPS alone or EPSPS + PDH45 overexpressing transgenic lines showed less affinity to glyphosate treatment may be because of truncated EPSPS gene. Therefore, glyphosate treatment does not have any effect on shikimate level and remained comparable to the control treatment without glyphosate. The results show that the truncated EPSPS gene is lesser impacted by glyphosate. Before treatment, WT, VC or all the transgenic plants showed similar shikimate levels, while treatment with $1 \mathrm{mM}$ glyphosate increased the levels of shikimate in leaves of WT, VC or PDH45 transgenic plants up to 21 DPS (Figure 3D). However, significantly lesser accumulation of shikimate was observed in EPSPS or PDH45+EPSPS transgenics (Figure 3D). These results clearly confirm major role of the EPSPS gene in providing herbicide tolerance.

\section{Dual Gene (PDH45 + EPSPS) Transgenic Plants Accumulate Less MDA, $\mathrm{H}_{2} \mathrm{O}_{2}$ and Ion Leakage and Show Better Antioxidant and Photosynthetic Response under Salinity Stress}

Salinity induced changes in the accumulation of MDA (malondialdehyde; by product of lipid peroxidation), $\mathrm{H}_{2} \mathrm{O}_{2}$ and ion leakage were quantified in $\mathrm{T}_{1}$ tobacco transgenics along with WT or VC plants as important stress biomarkers. Significantly reduced levels of MDA, ion leakage or $\mathrm{H}_{2} \mathrm{O}_{2}$ (Figures 4A-C) accompanied with induced activities of antioxidant enzymes 

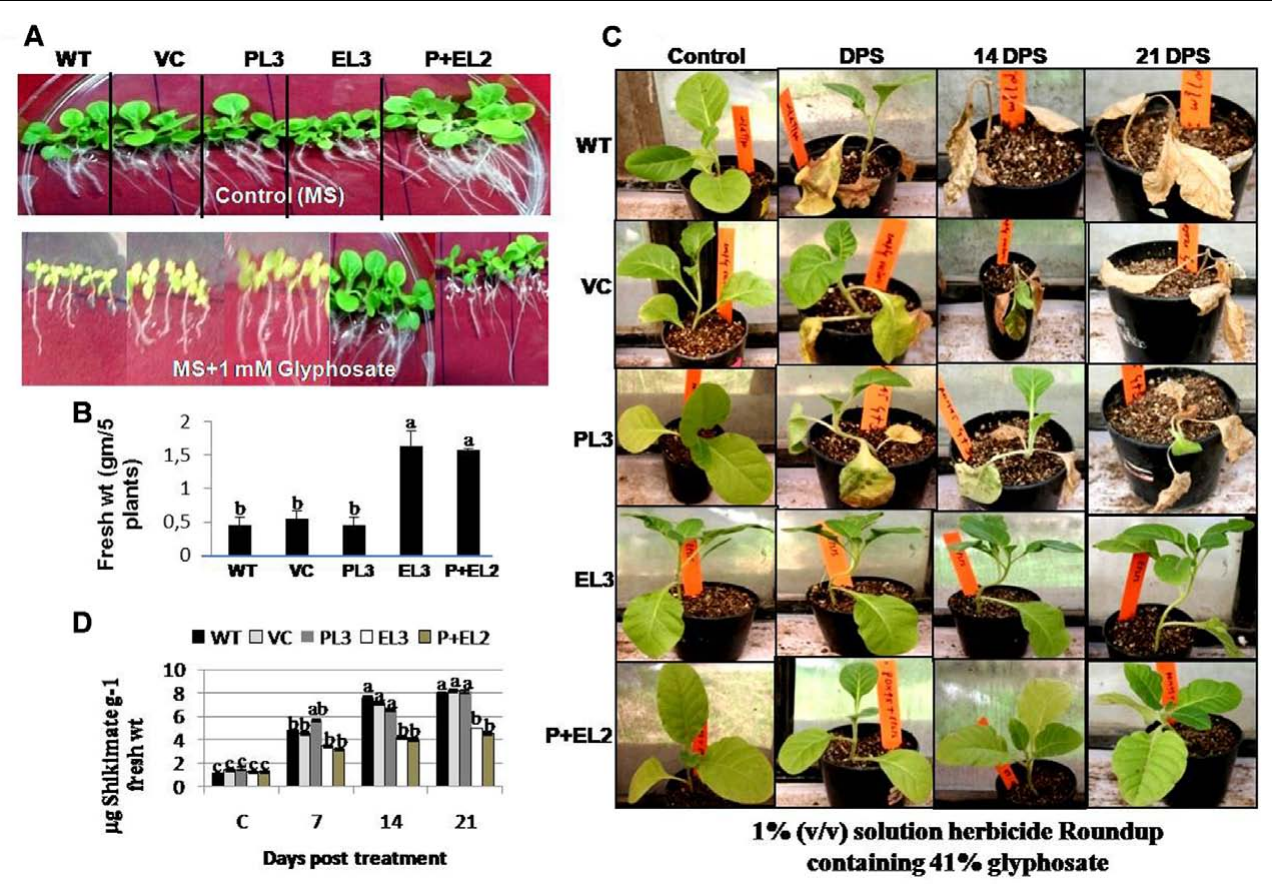

FIGURE 3 | Glyphosate tolerance of PDH45 (P), EPSPS (E) and PDH45+EPSPS (P+E) transgenics, VC and WT plants in green house, when sprayed with $1 \%(\mathbf{v} / \mathbf{v})$ solution herbicide Roundup containing $\mathbf{4 1} \%$ glyphosate. (A) $\mathrm{T}_{1}$ tobacco seedlings were germinated on the plain MS and MS containing $1 \mathrm{mM}$ glyphosate and grown for 7 days at $100 \mu \mathrm{mol} \mathrm{m} \mathrm{m}^{-2}$ with $16 \mathrm{~h} \mathrm{L/8} \mathrm{h} \mathrm{dark} \mathrm{period.} \mathrm{(B)} \mathrm{Fresh} \mathrm{weight} \mathrm{of} \mathrm{seedlings} \mathrm{was} \mathrm{recorded.} \mathrm{(C)} \mathrm{These} \mathrm{seedlings} \mathrm{were} \mathrm{further}$ transferred to the soil in pots and grown for another month. Six to eight leaf stage transgenic plants were sprayed with $1 \%$ (v/v) solution herbicide Roundup containing 41\% glyphosate. After 7 DPS (days post spray), 14 and 21 DPS, injury was observed. Photographs of tobacco seedlings have been taken after spray at above mentioned time points. Plants used for spray were further used for shikimate estimation. (D) Accumulation of shikimate content was determined in transgenic lines and WT plants. Experiment was repeated twice in three independent plants. Data represent the means \pm SD of three independent experiments $(n=3)$,

${ }^{\mathrm{a}} \mathrm{P}<0.05,{ }^{\mathrm{b}} \mathrm{P}<0.01,{ }^{\mathrm{c}} \mathrm{P}<0.001$.

such as CAT, APX, or GR (Figures 4D-F) were observed in PDH45 or PDH45+EPSPS transgenic plants as compared to WT, VC or EPSPS transgenic plants. As a part of antioxidant defense in plants, proline accumulation was also found to be higher in PDH45 or PDH45+EPSPS transgenic lines as compared to WT, VC or EPSPS transgenic plants (Figure 4G), which further led to efficient maintenance of higher water balance (Figure $4 \mathbf{H}$ ) under salinity stress.

$\mathrm{H}_{2} \mathrm{O}_{2}$ detection and quantification were performed using 3, 3-diaminobenzidine (DAB) staining method. Polymerization of $\mathrm{DAB}$, visible as brown precipitate against $\mathrm{H}_{2} \mathrm{O}_{2}$ was detected in WT, VC or all the transgenic tobacco plants, while significantly lesser $\mathrm{H}_{2} \mathrm{O}_{2}$ accumulation was detected in PDH45 or PDH45+EPSPS plants as compared to WT, VC or EPSPS overexpressing lines (Figure 4I), which showed marked increase in $\mathrm{H}_{2} \mathrm{O}_{2}$ accumulation under salinity treatment (Figure 4I). Besides that $\mathrm{O}_{2}{ }^{-}-$detection and quantification were performed using NBT staining method after $24 \mathrm{~h}$ of salinity treatment. The results revealed accumulation of $\mathrm{O}_{2}{ }^{--}$in the form of blue color in all transgenics or WT plants; the blue color was comparatively more in EPSPS transgenic plants along with WT and VC (Figure 4J). Furthermore, the accumulation pattern of $\mathrm{O}_{2}{ }^{--}$and $\mathrm{H}_{2} \mathrm{O}_{2}$ shown by NBT and DAB staining can be arbitrary and only reflective in nature. The NBT and $\mathrm{DAB}$ tests were performed after salinity stress in control and transgenic lines and may not reflect as under natural conditions. Parameters of photosynthesis efficiency were quantified after exposure to $24 \mathrm{~h}$ salinity stress in tobacco transgenics along with WT and VC plants. Net photosynthetic rate, yield, stomatal conductance or transpiration rates were found to be higher in PDH45 and PDH45+EPSPS transgenic plants in comparison to WT, VC or EPSPS transgenic plants (Figures $\mathbf{5 A - C , F}$ ). Moreover, $\mathrm{PDH} 45$ or PDH45+EPSPS transgenic plants showed marked increase in respiration (Figures 5D,E), indicating higher and constant photosynthetic rates even under salinity stress, whereas, WT, VC or EPSPS transgenics plants were strongly affected.

\section{PDH45 Modulates Jasmonic and Salicylic Acid Signaling Pathways for Salinity Tolerance}

Finally, to study the effect of PDH45 overexpression in transgenic lines on the expression of stress and hormonal markers, we designed 19 pair of primers (Supplementary Table S1) related to different abiotic stress marker and hormonal pathways related genes to study their expression level in transgenic plant (PDH45, EPSPS, or PDH45+EPSPS). Genes related to cell death marker, upstream of $\mathrm{ABA}$ signaling, transcription factors in $\mathrm{ABA}$ signaling, $\mathrm{ABA}$ responsive genes, ethylene 

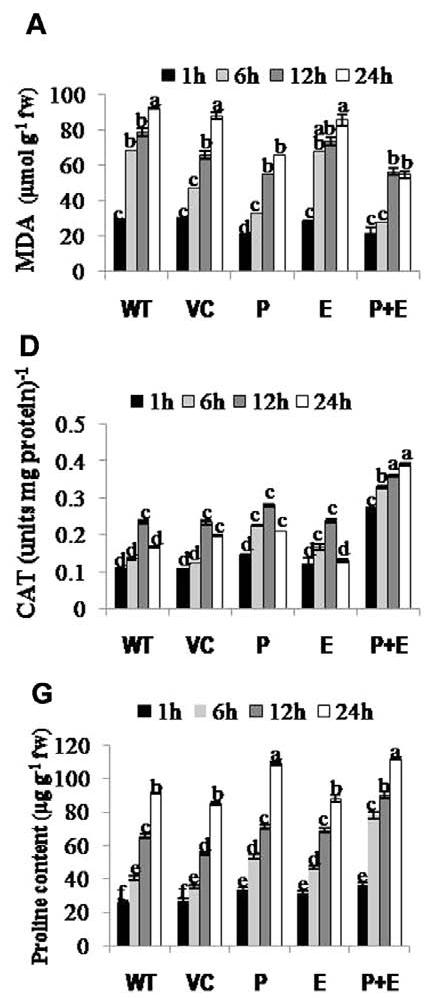

B

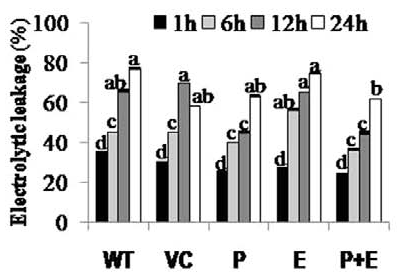

E
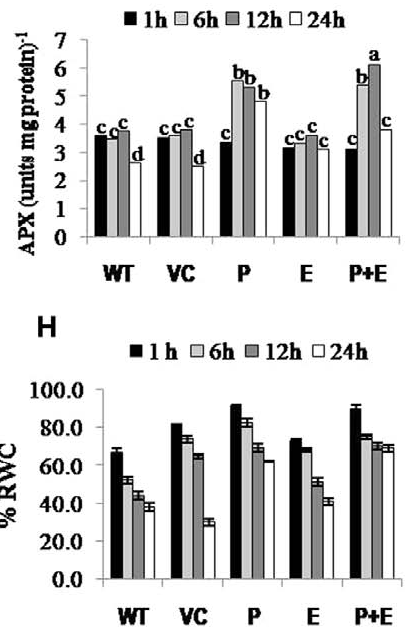

C

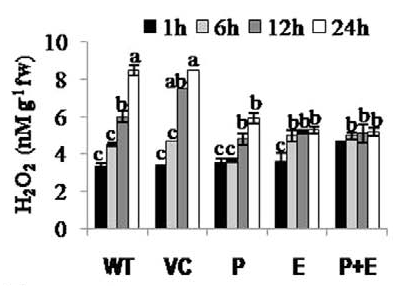

$\mathbf{F}$
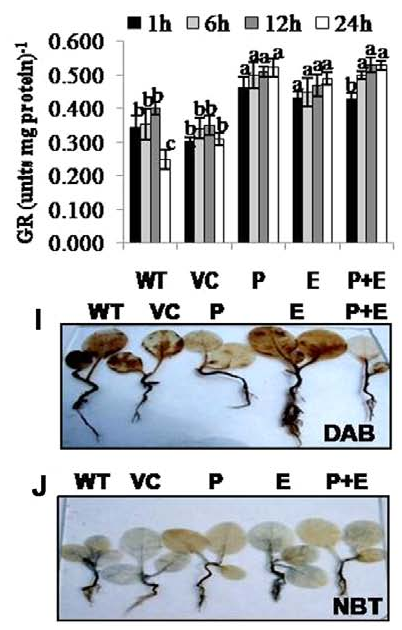

FIGURE 4 | Biochemical analysis of PDH45 (P), EPSPS (E) and PDH45+EPSPS (P+E) transgenics, VC and WT plants under $200 \mathrm{mM}$ NaCl conditions. (A) Determination of lipid peroxidation expressed in terms of MDA content in transgenic lines, WT and VC. (B) Estimation of percentage electrolytic leakage in transgenic lines, WT and VC. (C) Changes in the level of hydrogen peroxide $\left(\mathrm{H}_{2} \mathrm{O}_{2}\right)$ content in transgenic lines along with WT and VC. (D) Catalase (CAT) activity in transgenic lines, WT and VC. One unit of enzyme activity is defined as $1 \mu \mathrm{mol} \mathrm{H}_{2} \mathrm{O}_{2}$ oxidized $\mathrm{min}^{-1}$. (E) Changes in ascorbate peroxidase (APX) enzyme activity in transgenic lines, WT and VC. One unit of enzyme activity defined as $1 \mu \mathrm{mol}$ of ascorbate oxidized $\mathrm{min}^{-1}$. (F) Changes in glutathione reductase (GR) enzyme activity in transgenic lines, WT and VC. One unit of enzyme activity is defined as $1 \mu \mathrm{mol}$ of GS-TNB formed $\mathrm{min}^{-1}$ due to reduction of DTNB. (G) Changes in the level of proline accumulation in transgenic lines, WT and VC. (H) Estimation of percent relative water content (RWC) in PDH45, EPSPS and PDH45+EPSPS transgenic lines, WT and VC. (I) Detection of hydrogen peroxide $\left(\mathrm{H}_{2} \mathrm{O}_{2}\right)$ accumulation using 3, 3-diaminobenzidine (DAB) staining method. (J) Detection of superoxide radical $\left(\mathrm{O}_{2} \cdot{ }^{\bullet-}\right)$ accumulation using nitroblue tetrazolium (NBT) staining method. Data represent the means \pm SD of three independent experiments $(n=3)$, ${ }^{a} P<0.05$, ${ }^{b} P<0.01$, ${ }^{c} P<0.001$

pathway marker genes, jasmonic acid (JA) pathway, SA and ROS pathway marker genes were found to be significantly induced in all the transgenic (Figure 6A) under salinity treatment. Interestingly, especially for salinity treated $\mathrm{PDH} 45$ or PDH45+EPSPS transgenic plants, expression level of JA pathway related genes including $N t D E F$ and $N t A O S$ (allene oxide synthase) were significantly higher than the expression of other pathway related genes. Moreover, SA pathway genes such as NtICS1 and NtPR2 also responded effectively with genes related to JA pathway in operating salinity tolerance mechanism in PDH45 or PDH45+EPSPS transgenic plants. However, EPSPS overexpressing plants were observed to utilize ABA (NtADH and NtERD) and ROS pathway (NtAPX and NtDHAR) marker genes to defend against stress. For further confirmation of MeJ and SA mediated signaling pathway opted by PDH45 or PDH45+EPSPS against salinity stress, we germinated the seeds of all transgenic lines along with WT and VC plants in MS medium (control) and MS medium supplemented with $\mathrm{MeJ}, \mathrm{SA}$, or $\mathrm{MeJ}+\mathrm{SA}$. In the presence of MeJ, SA or MeJ+SA hormones, the PDH45, PDH45+EPSPS showed early and efficient germination rate as compared to $\mathrm{WT}, \mathrm{VC}$ or EPSPS transgenic plants (Figures 6B-D). However, in control conditions all the transgenics, VC or WT had similar germination rate (Figure 6E).

\section{Analysis of $T_{2}$ Generation Transgenic Plants}

The $\mathrm{T}_{2}$ generation transgenic plants from all the lines (PDH45, EPSPS, or PDH45+EPSPS) were also raised and found positive as checked by gene specific primers (Supplementary Figures S1A-D). The $\mathrm{T}_{2}$ transgenic seeds of $\mathrm{PDH} 45$ or PDH45+EPSPS transgenic plants germinated and grew efficiently under $200 \mathrm{mM} \mathrm{NaCl}$, while the WT, VC or EPSPS transgenic seeds germinated weakly and showed reduced growth and turned yellow (Supplementary Figure S1E). In the leaf disk assay, the salinity stress induced loss of chlorophyll was quantified in $\mathrm{T}_{2}$ transgenics. As a result, \% retained chlorophyll was higher in PDH45 or PDH45+EPSPS transgenic plants in comparison to WT, VC or EPSPS overexpressing lines, under $200 \mathrm{mM} \mathrm{NaCl}$ as 

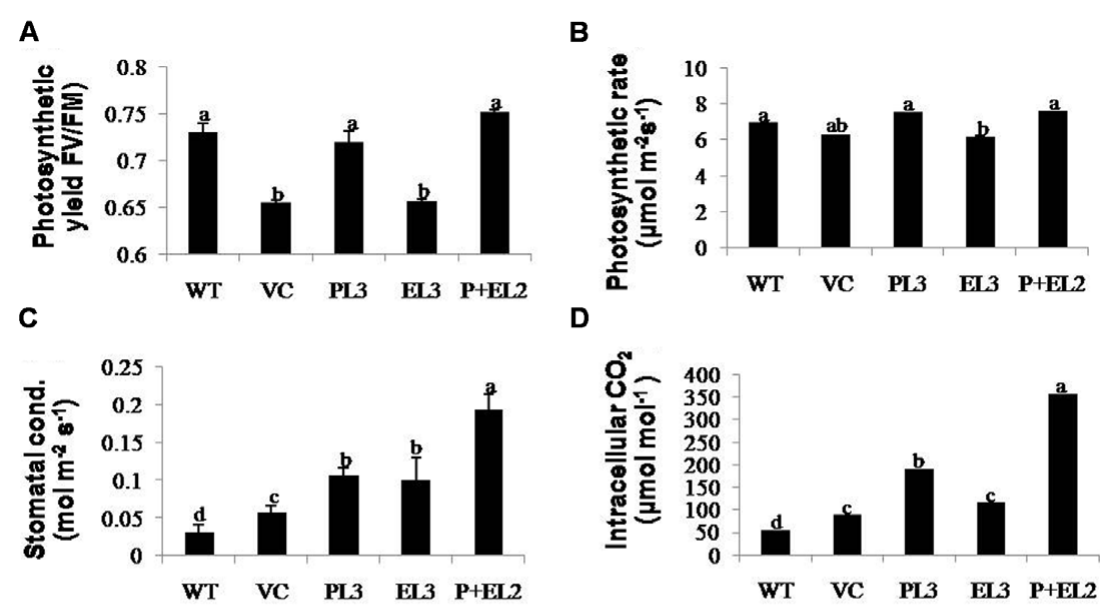

D

E

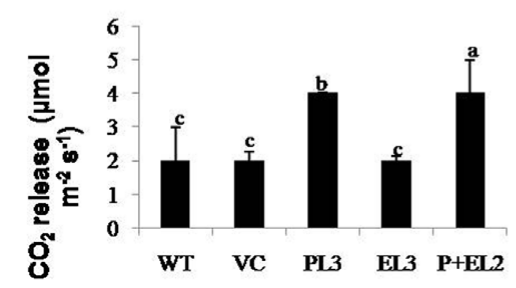

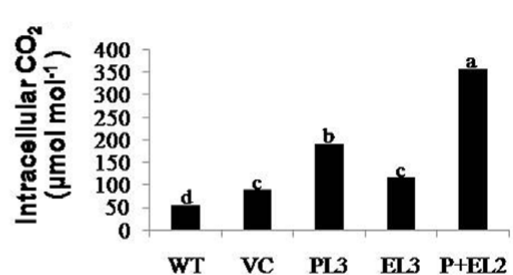

F

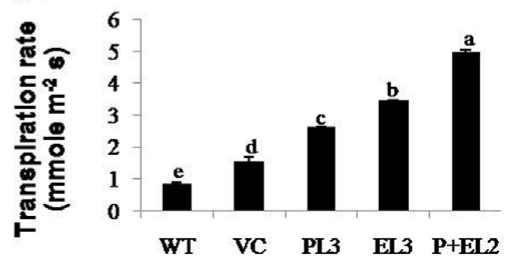

FIGURE 5 | Determinations of changes in photosynthetic machinery were performed by IRGA in transgenics including PDH45 (P), EPSPS (E) and PDH45+EPSPS (P+E), VC and WT plants under salinity stress. Fully expanded leaves were chosen for measurement of photosynthetic activity under constant sunlight. (A) Photosynthetic yield FV/Fm. (B) Measurement of photosynthesis rate. (C) Stomatal conductance. (D,E) Quantification of intracellular and released $\mathrm{CO}_{2}$. (F) Measurement of transpiration rate against $200 \mathrm{mM}$ salinity stress. Data are shown as the average of $\pm \mathrm{SD}$ of three independent transgenic plants, $P<0.05$, $P<0.01, P<0.001$. The letters a, b, c, d, and e indicate significant differences.

checked by quantification of chlorophyll content in the leaf disks after 72 h (Supplementary Figure S1F).

\section{DISCUSSION}

Being sessile, plants are continuously encounter abiotic stress conditions that impose serious detrimental effects and cause significant decline in crop productivity (Gururani et al., 2015). Among abiotic stresses, high salinity, weed stress or herbicide stress cause serious alteration in growth responses and damage to photosynthetic machinery. Plants have evolved several mechanisms to perceive and transmit signals to cellular machinery that eventually activates responses in terms of abiotic and biotic stress management (Thomashow, 1999; Xiong et al., 2002; Mahajan and Tuteja, 2005). The understanding of stress tolerance mechanism against various stress factors may prove beneficial for developing tolerant crop plants. Hence, in this context, we have earlier shown that overexpression of single gene (PDH45, PDH47, SUV3, or p68) in tobacco and rice transgenic plants resulted in high salinity stress tolerance without any yield penalty (Sanan-Mishra et al., 2005; Vashisht et al., 2005; Amin et al., 2012; Gill et al., 2013; Tuteja et al., 2013, 2014; Banu et al., 2015). In addition to the salinity stress, weeds are also considered as one of the major problem for agricultural productivity. Regarding that EPSPS has been reported as a promising gene for its role in glyphosate effect (Cao et al., 2013; Délye et al., 2013). Therefore, these findings encouraged us to generate transgenic plants having dual characteristics of salinity and herbicide tolerance, harboring both the PDH45 and EPSPS genes as salinity and herbicide tolerant genes, respectively. In the era of frequently changing environmental conditions, there is an urgent need of developing crops with multiple stress tolerance features. Therefore, our research provides novel insights into developing transgenics with multiple traits of salinity tolerance and herbicide resistance without the yield loss.

The PDH45 alone and PDH45+EPSPS double construct overexpressing transgenic tobacco plants showed tolerance against salinity as observed by higher chlorophyll retention and percent germination potential, in comparison to WT, VC and EPSPS overexpressing plants. Moreover, $\mathrm{T}_{1}$ seedlings of $\mathrm{PDH} 45$ and $P D H 45+E P S P S$ transgenics plants were able to survive, flower and set viable seeds even under salinity stress. These observations suggest that foreign trait is functionally active and stable in transgenic plants. In addition to salinity stress treatment, glyphosate spray on different transgenic and WT, VC plants revealed that the EPSPS overexpressing transgenic plants showed lesser injury and survived better, whereas, PDH45, WT and VC were injured, dried and finally could not survived. The treatment of plants with glyphosate might have inhibited the EPSPS activity and led to the accumulation of shikimate (Barry and Padgette, 


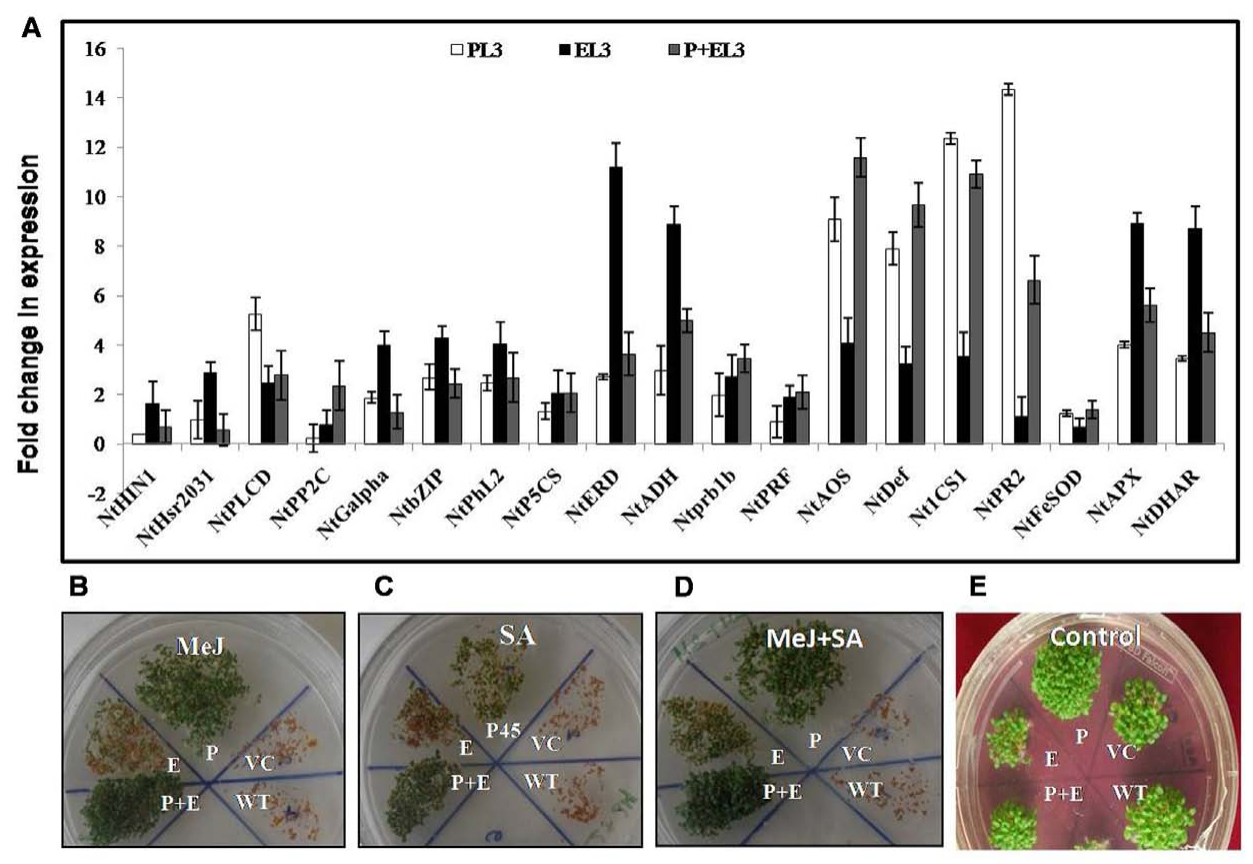

FIGURE 6 | (A) qPCR analysis of various abiotic stress marker and hormonal pathway related genes (NtHin1, NtHsr2031: cell death marker NtPLCD; NtPP2C; NtGalpha: upstream of ABA signaling, NtbZIP; NtPhl2: transcription factors in ABA signaling, NtP5CS; NtERD; NtADH: ABA responsive genes, NtADH; NtPrb1b; NtPRF: ethylene pathway marker genes, NtAOS; NtDef: jasmonic acid pathway marker genes, Nt/CS1; Nt PR2: salicylic acid pathway marker genes, NtFeSOD; NtAPX; NtDHAR: ROS pathway marker genes) in PDH45 (P), EPSPS (E), and double construct containing PDH45+EPSPS (P+E). (B-E) Seedling establishment of all transgenic lines along with WT and VC plants in $10 \mu \mathrm{M} \mathrm{MeJ,} 0.2 \mathrm{mM} \mathrm{SA}$, and $10 \mu \mathrm{M}$ Mej+0.2 mM SA hormones. (B) Seedling establishment in MeJ. (C) Seedling establishment of transgenic lines along with VC in SA. (D) Seedling establishment of transgenic lines along with VC in Mej+SA. (E) Seedling establishment of transgenic lines along with VC in Plain MS medium as a control.

1992; Chang et al., 2003; Délye et al., 2013). Moreover, it has been observed that glyphosate treatment caused accumulation of shikimate in glyphosate insensitive tobacco cells, whereas, lack of shikimate accumulation was found in tolerant cells (Tian et al., 2010). In tune with above studies, treatment with $1 \mathrm{mM}$ glyphosate induced the accumulation of shikimate in both WT and transgenic plants but the accumulation of shikimate was lower in transgenic plants overexpressing EPSPS gene. This finding confirmed the role of EPSPS gene as an active target for glyphosate action. Previously reported studies also focused on isolation and characterization of $R$. aqualilis strain EPSPS in tobacco significantly reduced the glyphosate sensitivity (Peng et al., 2012). Besides that, Cao et al. (2013) proved the role of five bacterial gene coding for EPSPS in the E. coli and transgenic tobacco against glyphosate. Overexpression of codon-optimized CP4-EPSPS in rice helped the transgenic plants to tolerate up to 1\% commercial glyphosate treatment (Chhapekar et al., 2015). Further, stacking of $\mathrm{Bt}$ cry1Ah and mG2-epsps gene linked with LP4/2A showed higher expression and possessed good pest resistance and glyphosate tolerance in tobacco than those linked by $2 \mathrm{~A}$ (Sun et al., 2012).

It has been proposed that ROS accumulation $\left(\mathrm{O}_{2}{ }^{-}-, \mathrm{H}_{2} \mathrm{O}_{2}\right.$, etc.) during salinity stress caused accumulation of MDA, damage to cellular macromolecules and eventually affects the stability of membranes (Apel and Hirt, 2004; Gill and Tuteja, 2010; Gill et al., 2012; Das and Roychoudhury, 2014). In the present study, we showed that PDH45 and PDH45+EPSPS transgenic plants represent less $\mathrm{O}_{2}{ }^{\bullet-}$ and $\mathrm{H}_{2} \mathrm{O}_{2}$ accumulation thus significantly lesser lipid peroxidation, $\mathrm{H}_{2} \mathrm{O}_{2}$ content and ion leakage along with increased activities of antioxidant enzymes including CAT, APX, and GR. The efficient ROS scavenging activities of antioxidant enzymes triggered by ROS and higher accumulation of osmoprotectants in PDH45 and PDH45+EPSPS transgenic plants could be one of the reasons in maintaining the integrity of membranes for the plant survival under the stress. Our results and previously reported studies in rice (Gill et al., 2013) also suggest delayed senescence in PDH45 overexpressing transgenic plants which was co-related with increased tolerance to oxidative stress.

PDH45 and PDH45+EPSPS overexpressing transgenic plants showed lesser damage to photosynthetic apparatus, thus maintaining the normal growth and yield of transgenic plants, whereas, WT and VC experienced maximum damage to photosynthesis machinery under $200 \mathrm{mM} \mathrm{NaCl}$ stress. In general the reduction in photosynthesis with increased salinity stress could be attributed to the difference in the efficiency of root system in limiting the transport of ions to shoots (Mahajan and Tuteja, 2005; Munns et al., 2006; Gill et al., 2013). Furthermore, the inefficiency of photosynthesis under salinity stress may be due to stomatal exposure under water deficiency 
(Meloni et al., 2003) in addition to impaired several biochemical and physiological process like imbalance between ROS and their scavenging system (Sultana et al., 1999; Gill and Tuteja, 2010; Das and Roychoudhury, 2014).

In order to gain insights regarding pathway utilized by PDH45 and PDH45+EPSPS transgenic plants in tolerating salinity stress, we performed expression studies for 19 genes related to abiotic stress marker and hormonal pathways. However, the pathways, utilized by $\mathrm{PDH} 45$ gene in providing salinity tolerance is still obscure. Our studies showed the maximum transcript accumulation AOS (allene oxide synthase) and NtDef genes related to JA pathways and demonstrate that PDH45 and PDH45+EPSPS transgenic plants can induce JA production and could promote the accumulation of secondary metabolites for the survival of plants under salinity stress. As an important signal molecule, JA (endogenous regulator) plays a key role in regulating stress responses, plant growth and development (Turner et al., 2002; Qiu et al., 2014). It has been reported that the exogenous application of $2 \mathrm{mM} \mathrm{JA}$ on wheat seedlings under salinity stress resulted in significant decrease in MDA, $\mathrm{H}_{2} \mathrm{O}_{2}$ content, $\mathrm{O}_{2}{ }^{-}$radical production and significant increase in the transcript levels of SOD, POD, CAT and APX and GSH content, chlorophyll $b$ and carotenoids content (Qiu et al., 2014). In addition to JA, SA also acted as a signal molecule in providing salinity tolerance to PDH45 and PDH45+EPSPS transgenic plants. Cross-talk between different signal transduction pathways as opposed to single signaling pathways, mediates gene expression and production of secondary metabolites during plant defense responses (Reymond and Farmer, 1998; Mur et al., 2006; Khan et al., 2015).

Interestingly, present work reports the synergistic effect of JA related genes with SA signaling pathways genes. Though, JA is commonly postulated to act antagonistically on the SA regulating pathways and on the expression of SA dependent genes (Kachroo et al., 2001; Kloek et al., 2001). In parallel to that, both JA and SA are also considered as the important signal molecules in plant defense responses (Kunkel and Brooks, 2002; Shah, 2003; Qiu

\section{REFERENCES}

Amin, M., Elias, S. M., Hossain, A., Ferdousi, A., Rahman, M. S., Tuteja, N., et al. (2012). Overexpression of a DEAD box helicase, PDH45, confers both seedling and reproductive stage salinity tolerance to rice (Oryza sativa L.). Mol. Breed. 30, 345-354. doi: 10.1007/s11032-0119625-3

Apel, K., and Hirt, H. (2004). Reactive oxygen species: metabolism, oxidative stress, and signal transduction. Annu. Rev. Plant Biol. 55, 373-399. doi: 10.1146/ annurev.arplant.55.031903.141701

Banu, M. S. A., Huda, K. M. K., Shaoo, R. K., Garg, B., Tula, S., Islam, S. M. S., et al. (2015). Pea p68 imparts salinity stress tolerance in rice by scavenging of ROSmediated $\mathrm{H}_{2} \mathrm{O}_{2}$ and interacts with argonaute. Plant Mol. Biol. Rep. 33, 221-238. doi: 10.1007/s11105-014-0748-7

Barry, G., and Padgette, S. R. (1992). Glyphosate tolerant 5-enolpyruvylshikimate3-phosphate synthases. WO 92/04449.

Cao, G., Liu, Y., Zhang, S., Yang, X., Chen, R., Zhang, Y., et al. (2013). A novel 5enolpyruvyl shikimate -3-phosphate synthase shows high glyphosate tolerance in Escherichia coli and tobacco plants. PLoS ONE 7:e38718. doi: 10.1371/journal. pone.0038718 et al., 2014; Khan et al., 2015). Overall results suggest that PDH45 and PDH45+EPSPS may play a critical role in plant response against salinity stress and might act as a component of JA and SA mediated signaling pathways. However, the confirmation of JA and SA pathways modulated by PDH45 and PDH45+EPSPS in tobacco response to salinity stress need to be investigated further. Thus, finally it can be concluded that pyramiding of the PDH45 gene with EPSPS gene renders host plants tolerant to salinity and herbicide by enhancing antioxidant machinery through modulation of JA and SA mediated signaling pathways.

\section{GENE BANK ACCESSION NUMBERS}

PDH45 - Y17186.1, EPSPS - US2007/0180574A1.

\section{AUTHOR CONTRIBUTIONS}

The experimental set up was designed by NT, RT, BG, NK and SG and BG, DB, RS performed the experiments and acquired the data. NT, RT, BG, NK, and SG analyzed the data. BG, DB, NT, RT, NK, and SG interpreted the results and wrote the manuscript. NT and RT supervised the project.

\section{ACKNOWLEDGMENT}

NT would like to acknowledge the help of Department of Biotechnology (DBT), Government of India for providing partial financial support (Project no.: BT/BIPP/0196/03/09).

\section{SUPPLEMENTARY MATERIAL}

The Supplementary Material for this article can be found online at: http://journal.frontiersin.org/article/10.3389/fpls.2017.00364/ full\#supplementary-material

Chang, H. S., Kim, N. H., Park, M. J., Lim, S. K., Kim, S. C., Kim, J. Y., et al. (2003). The 5- enolpyruvylshikimate-3-phosphate synthase of glyphosatetolerant soybean expressed in Escherichia coli shows no severe allergenicity. Mol. Cell. 15, 20-26.

Chhapekar, S., Raghavendrarao, S., Pavan, G., Ramakrishna, C., Singh, V. K., Phanindra, M. L. V., et al. (2015). Transgenic rice expressing a codonmodified synthetic CP4-EPSPS confers tolerance to broad-spectrum herbicide, glyphosate. Plant Cell Rep. 34, 721-731. doi: 10.1007/s00299-014-1732-2

Cole, D., Pallett, K., and Rodgers, M. (2000). Discovering new modes of action for herbicides and the impact of genomics. Pestic Outlook 11, 223-229. doi: $10.1039 /$ b009272j

Cushman, J. C., and Bohnert, H. J. (2000). Genomic approaches to plant stress tolerance. Curr. Opin. Plant Biol. 3, 117-124. doi: 10.1016/S1369-5266(99) 00052-7

Das, K., and Roychoudhury, A. (2014). Reactive oxygen species (ROS) and response of antioxidants as ROS-scavengers during environmental stress in plants. Front. Environ. Sci. 2:53. doi: 10.3389/fenvs.2014.00053

Délye, C. (2013). Unravelling the genetic bases of non-target-site-based resistance (NTSR) to herbicides: a major challenge for weed science in the forthcoming decade. Pest Manag. Sci. 69, 176-187. doi: 10.1002/ps.3318 
Délye, C., Jasieniuk, M., and Le Corre, V. (2013). Deciphering the evolution of herbicide resistance in weeds. Trends Genet. 29, 649-658. doi: 10.1016/j.tig. 2013.06.001

Dong, C.-H., Zolman, B. K., Bartel, B., Lee, B.-H., Stevenson, B., Agarwal, M., et al. (2009). Disruption of Arabidopsis CHY1 reveals an important role of metabolic status in plant cold stress signaling. Mol. Plant 2, 59-72. doi: 10.1093/mp/ ssn063

Duke, S. O., and Powles, S. B. (2008). Glyphosate: a once-in-a-century herbicide. Pest Manag. Sci. 64, 319-325. doi: 10.1002/ps.1518

Funke, T., Han, H., Healy-Fried, M. L., Fischerm, M., and Schönbrunn, E. (2006). Molecular basis for the herbicide resistance of Roundup Ready crops. Proc. Natl. Acad. Sci. U.S.A. 103, 13010-13015. doi: 10.1073/pnas.0603638103

Garg, B., Jaiswal, J. P., Mishra, S., Tripathi, B. N., and Prasad, M. (2012). A comprehensive study on dehydration-induced antioxidative responses during germination of Indian bread wheat (Triticumae aestivum L. emThell) cultivars collected from different agroclimatic zones. Physiol. Mol. Biol. Plants 18, 217-228. doi: 10.1007/s12298-012-0117-7

Gill, S. S., Gill, R., Tuteja, R., and Tuteja, N. (2014). Genetic engineering of crops: a ray of hope for enhanced food security. Plant Signal. Behav. 9:e28545. doi: $10.4161 /$ psb.28545

Gill, S. S., Singh, L. P., Gill, R., and Tuteja, N. (2012). "Generation and scavenging of reactive oxygen species in plants under stress," in Improving Crop Resistance to Abiotic Stress, eds N. Tuteja, S. S. Gill, A. F. Tiburcio, and R. Tuteja (Weinheim: Wiley-VCH Verlag GmbH and Co. KGaA), 49-70. doi: 10.1002/ 9783527632930.ch3

Gill, S. S., Tajrishi, M., Madan, M., and Tuteja, N. (2013). DESD-box helicase functions in salinity stress tolerance by improving photosynthesis and antioxidant machinery in rice (Oryza sativa L. cv. PB1). Plant Mol. Biol. 82, 1-22. doi: 10.1007/s11103-013-0031-6

Gill, S. S., and Tuteja, N. (2010). Reactive oxygen species and antioxidant machinery in abiotic stress tolerance in crop plants. Plant Physiol. Biochem. 48, 909-939. doi: 10.1016/j.plaphy.2010.08.016

Gomes, M. P., Smedbol, E., Chalifour, A., Hénault-Ethier, L., Labrecque, M., Lepage, L., et al. (2014). Alteration of plant physiology by glyphosate and its byproduct aminomethylphosphonic acid: an overview. J. Exp. Bot. 65, 4691-4703. doi: $10.1093 /$ jxb/eru269

Green, J. M. (2012). The benefits of herbicide-resistant crops. Pest Manag. Sci. 68, 1323-1331. doi: 10.1002/ps.3374

Gururani, M. A., Venkatesh, J., and Tran, L. P. (2015). Regulation of photosynthesis during abiotic stress-induced photoinhibition. Mol. Plant 8, 1304-1320. doi: 10.1016/j.molp.2015.05.005

Huda, K. M. K., Banu, M. S. A., Garg, B., Tula, S., Tuteja, R., and Tuteja, N. (2013). OsACA6, a P-type IIB Ca2+ATPase promotes salinity and drought stress tolerance in tobacco by ROS scavenging and enhancing the expression of stress-responsive genes. Plant J. 76, 997-1015. doi: 10.1111/tpj. 12352

Kachroo, P., Shanklin, J., Shah, J., Whittle, E. J., and Klessig, D. F. (2001). A fatty acid desaturase modulates the activation of defense signaling pathways in plants. Proc. Natl. Acad. Sci. U.S.A. 98, 9448-9453. doi: 10.1073/pnas.151 258398

Khan, M. I., Fatma, M., Per, T. S., Anjum, N. A., and Khan, N. A. (2015). Salicylic acid-induced abiotic stress tolerance and underlying mechanisms in plants. Front. Plant Sci. 6:462. doi: 10.3389/fpls.2015.00462

Kloek, A. P., Verbsky, M. L., Sharma, S. B., Schoelz, J. E., Vogel, J., Klessig, D. F., et al. (2001). Resistance to Pseudomonas syringae conferred by an Arabidopsis thaliana coronatine insensitive (coil) mutation occurs through two distinct mechanisms. Plant J. 26, 509-522. doi: 10.1046/j.1365-313x.2001. 01050.x

Kunkel, B. N., and Brooks, D. M. (2002). Cross talk between signaling pathways inpathogen defense. Curr. Opin. Plant Biol. 5, 325-331. doi: 10.1016/S13695266(02)00275-3

Mahajan, S., and Tuteja, N. (2005). Cold, salinity and drought stresses: an overview. Arch. Biochem. Biophys. 444, 139-158. doi: 10.1016/j.abb.2005.10.018

Meloni, D. A., Oliva, A. A., Martinez, Z. A., and Cambraia, J. A. (2003). Photosynthesis and activity of superoxide dismutase, peroxidase and glutathione reductase in cotton under salt stress. Environ. Exp. Bot. 49, 69-76. doi: 10.1016/S0098-8472(02)00058-8
Mittler, R., Vanderauwera, S., Gollery, M., and Van Breusegem, F. (2004). The reactive oxygen gene network of plants. Trends Plant Sci. 9, 490-498. doi: 10.1016/j.tplants.2004.08.009

Munns, R., James, R. A., and Lauchli, A. (2006). Approaches to increasing the salt tolerance of wheat and other cereals. J. Exp. Bot. 57, 1025-1043. doi: 10.1093/ jxb/erj100

Mur, L. A. J., Kenton, P., Atzorn, R., Miersch, O., and Wasternack, C. (2006). The outcomes of concentration specific interactions between salicylate and jasmonate signaling include synergy, antagonism, and oxidative stress leading to cell death. Plant Physiol. 140, 249-262. doi: 10.1104/pp.105.072348

Owttrim, G. W. (2013). RNA helicases: diverse roles in prokaryotic response to abiotic stress. RNA Biol. 10, 96-110. doi: 10.4161/rna.22638

Pathi, K., Tula, S., and Tuteja, N. (2013). High frequency regeneration via direct somatic embryogenesis and efficient Agrobacterium-mediated genetic transformation of tobacco. Plant Signal. Behav. 8:e24354. doi: 10.4161/psb. 24354

Peng, R. H., Tiann, Y. S., Xiong, A. S., Zhao, W., Fu, X. Y., Han, H. J., et al. (2012). A novel 5-enoylpyruvylshikimate-3-phosphatesynthase from Rahnella aquatilis with significantly reduced glyphosate sensitivity. PLoS ONE 7:e39579. doi: 10.1371/journal.pone.0039579

Pham, X. H., Reddy, M. K., Ehtesham, N. Z., Matta, B., and Tuteja, N. (2000). A DNA helicase from Pisum sativum is homologous to translation initiation factor and stimulates topoisomerase I activity. Plant J. 24, 219-229. doi: 10. 1046/j.1365-313x.2000.00869.x

Qiu, Z. B., Guo, J. L., Zhu, A. J., Zhang, L., and Zhang, M. M. (2014). Exogenous jasmonic acid can enhance tolerance of wheat seedlings to salt stress. Ecotoxicol. Environ. Saf. 104, 202-208. doi: 10.1016/j.ecoenv.2014.03.014

Reymond, P., and Farmer, E. E. (1998). Jasmonate and salicylate as global signals for defense gene expression. Curr. Opin. Plant Biol. 1, 404-411. doi: 10.1016/ S1369-5266(98)80264-1

Sammons, R. D., and Gaines, T. A. (2014). Glyphosate resistance: state of knowledge. Pest Manag. Sci. 70, 1367-1377. doi: 10.1002/ps.3743

Sanan-Mishra, N., Pham, X. H., Sopory, S. K., and Tuteja, N. (2005). Pea DNA helicase 45 overexpression in tobacco confers high salinity tolerance without affecting yield. Proc. Natl. Acad. Sci. U.S.A. 102, 509-514. doi: 10.1073/pnas. 0406485102

Shah, J. (2003). The salicylic acid loop in plant defense. Curr. Opin. Plant Biol. 6, 365-371. doi: 10.1016/S1369-5266(03)00058-X

Simarmata, M., and Penner, D. (2008). The basis for glyphosate resistance in rigid ryegrass (Lolium rigidum) from California. Weed Sci. 56, 181-188. doi: 10.1614/WS-07-057.1

Sultana, N., Ikeda, T., and Itoh, R. (1999). Effect of $\mathrm{NaCl}$ salinity on photosynthesis and dry matter accumulation in developing rice grains. J. Environ. Exp. Bot. 42, 211-220. doi: 10.1016/S0098-8472(99)00035-0

Sun, H., Lang, Z., Zhu, L., and Huang, D. (2012). Acquiring transgenic tobacco plants with insect resistance and glyphosate tolerance by fusion gene transformation. Plant Cell Rep. 31, 1877-1887. doi: 10.1007/s00299-012-1301-5

Thomashow, M. F. (1999). Plants cold acclimation: freezing tolerance genes and regulatory mechanisms. Annu. Rev. Plant Physiol. Plant Mol. Biol. 50, 571-599. doi: 10.1146/annurev.arplant.50.1.571

Tian, Y. S., Xiong, A. S., Xu, J., Zhao, W., Gao, F., Fu, X. Y., et al. (2010). Isolation from Ochrobactrum anthropi of a novel class II 5-enopyruvylshikimate-3phosphate synthase with high tolerance to glyphosate. Appl. Environ. Microbiol. 76, 6001-6005. doi: 10.1128/AEM.00770-10

Turner, J. G., Ellis, C., and Devoto, A. (2002). The jasmonate signal pathway. Plant Cell 14, S153-S164. doi: 10.1105/tpc.000679

Tuteja, N. (2007). Mechanisms of high salinity tolerance in plants. Methods Enzymol. 428, 419-438. doi: 10.1016/S0076-6879(07)28024-3

Tuteja, N., Banu, M. S. A., Huda, K. M. K., Gill, S. S., Jain, P., Pham, X. H., et al. (2014). Pea p68, a DEAD-box helicase, provides salinity stress tolerance in transgenic tobacco by reducing oxidative stress and improving photosynthesis machinery. PLOS ONE 9:e98287. doi: 10.1371/journal.pone.0098287

Tuteja, N., Gill, S. S., and Tuteja, R. (2012). "Helicases in improving abiotic stress tolerance in crop plants," in Improving Crop Resistance to Abiotic Stress, Vols 1 and 2, eds N. Tuteja, S. S. Gill, A. F. Tiburcio, and R. Tuteja (Weinheim: WileyVCH Verlag GmbH \& Co. KGaA), 435-447. doi: 10.1002/9783527632930. ch19 
Tuteja, N., Sahoo, R. K., Garg, B., and Tuteja, R. (2013). OsSUV3 dual helicase functions in salinity stress tolerance by maintaining photosynthesis and antioxidant machinery in rice (Oryza sativa L. cv. IR64). Plant J. 76, 115-127. doi: $10.1111 /$ tpj.12277

Tuteja, N., and Tuteja, R. (2004). Prokaryotic and eukaryotic DNA helicases: essential molecular motor proteins for cellular machinery. Eur. J. Biochem. 271, 1835-1848. doi: 10.1111/j.1432-1033.2004.04093.x

Vashisht, A. A., Pradhan, A., Tuteja, R., and Tuteja, N. (2005). Cold and salinity stress induced bipolar pea DNA helicases 47 involved in protein kinase C. Plant J. 44, 76-87. doi: 10.1111/j.1365-313X.2005. 02511.x

Vashisht, A. A., and Tuteja, N. (2006). Stress responsive DEAD-box helicases: a new pathway to engineer plant stress tolerance. J. Photochem. Photobiol. 84, 150-160. doi: 10.1016/j.jphotobiol.2006.02.010

Wakabayashi, K., and Böger, P. (2002). Target sites for herbicides: entering the 21st century. Pest Manag. Sci. 58, 1149-1154. doi: 10.1002/ ps. 560
Xiong, L., Schumaker, K. S., and Zhu, K. J. (2002). Cell signalling during cold, drought and salinity stress. Plant Cell 14, 165-183. doi: 10.1105/tpc.000596

Zhang, H. K., and Blumwald, E. (2001). Transgenic salt-tolerant tomato plants accumulate salt in foliage but not in fruit. Nat. Biotechnol. 19, 765-768. doi: $10.1038 / 90824$

Conflict of Interest Statement: The authors declare that the research was conducted in the absence of any commercial or financial relationships that could be construed as a potential conflict of interest.

Copyright (c) 2017 Garg, Gill, Biswas, Sahoo, Kunchge, Tuteja and Tuteja. This is an open-access article distributed under the terms of the Creative Commons Attribution License (CC BY). The use, distribution or reproduction in other forums is permitted, provided the original author(s) or licensor are credited and that the original publication in this journal is cited, in accordance with accepted academic practice. No use, distribution or reproduction is permitted which does not comply with these terms. 